Research Paper

\title{
Pancreatic Fat is not significantly correlated with $\beta$-cell Dysfunction in Patients with new-onset Type 2 Diabetes Mellitus using quantitative Computed Tomography
}

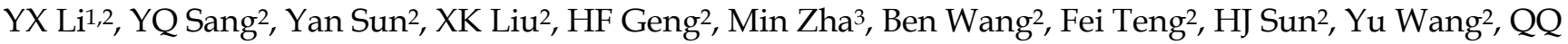 \\ $\mathrm{Qiu}^{2}$, Xiu Zang ${ }^{2}$, Yun Wang ${ }^{2}$, TT Wu ${ }^{2}$, Peter M. Jones ${ }^{4}$, Jun Liang ${ }^{2}$ and Wei Xu1,2, \\ 1. Graduate School of Bengbu Medical College, Bengbu, Anhui, China. \\ 2. Department of Endocrinology, Xuzhou Central Hospital, Xuzhou Institute of Medical Sciences, Xuzhou Clinical School of Nanjing Medical University, \\ Affiliated Hospital of Medical School of Southeast University, Jiangsu, China. \\ 3. Department of Endocrinology, Affiliated Hospital of Nanjing University of Chinese Medicine, Jiangsu Province Hospital of Chinese Medicine, Jiangsu, \\ China. \\ 4. Diabetes Research Group, Division of Diabetes \& Nutritional Sciences, School of Medicine, King's College London, London, UK. \\ $\triangle$ Corresponding authors: Wei Xu, E-mail: weixu159357@njmu.edu.cn; Jun Liang, E-mail: mwlj521@njmu.edu.cn.
}

(c) The author(s). This is an open access article distributed under the terms of the Creative Commons Attribution License (https://creativecommons.org/licenses/by/4.0/). See http://ivyspring.com/terms for full terms and conditions.

Received: 2020.03.27; Accepted: 2020.06.19; Published: 2020.07.02

\begin{abstract}
Objective: Type 2 diabetes mellitus (T2DM) is a chronic condition resulting from insulin resistance and insufficient $\beta$-cell secretion, leading to improper glycaemic regulation. Previous studies have found that excessive fat deposits in organs such as the liver and muscle can cause insulin resistance through lipotoxicity that affects $\beta$-cell function. The relationships between fat deposits in pancreatic tissue, the function of $\beta$-cells, the method of visceral fat evaluation and T2DM have been sought by researchers. This study aims to elucidate the role of pancreatic fat deposits in the development of T2DM using quantitative computed tomography (QCT), especially their effects on islet $\beta$-cell function.

Methods: We examined 106 subjects at the onset of T2DM who had undergone abdominal QCT. Estimated pancreatic fat and liver fat were quantified using QCT and calculated. We analysed the correlations with Homeostatic Model Assessment of Insulin Resistance (HOMA-IR) scores and other oral glucose tolerance test-derived parameters that reflect islet function. Furthermore, correlations of estimated pancreatic fat and liver fat with the area under the curve for insulin (AUCINS) and HOMA-IR were assessed with partial correlation analysis and demonstrated by scatter plots.

Results: Associations were found between estimated liver fat and HOMA-IR, AUCINs, the modified $\beta$-cell function index (MBCl) and Homeostatic Model Assessment $\beta$ (HOMA- $\beta$ ). However, no significant differences existed between estimated pancreas fat and those parameters. Similarly, after adjustment for sex, age and body mass index, only estimated liver fat was correlated with HOMA-IR and AUCINS.

Conclusions: This study suggests no significant correlation between pancreatic fat deposition and $\beta$-cell dysfunction in the early stages of T2DM using QCT as a screening tool. The deposits of fat in the pancreas and the resulting lipotoxicity may play an important role in the late stage of islet cell function dysfunction as the course of T2DM progresses.
\end{abstract}

Key words: Pancreatic fat; Quantitative computed tomography; Onset type 2 diabetes mellitus; $\beta$-cell function; Insulin resistance

\section{Introduction}

T2DM is a metabolic disease characterized by chronic hyperglycaemia that is related to both insulin resistance and defective insulin secretion [1]. Previous studies have shown that oxidative stress, low-grade chronic inflammation and activation of the renin-angiotensin system (RAS) all accelerate the development of T2DM [2-4]. With the emergence of unhealthy lifestyles characterized by sedentary 
behaviours and overnutrition, the increase in metabolic disorders caused by fatty acid spill-over has become a focus of research.

Many studies have demonstrated the contribution of lipotoxicity to the development of $\mathrm{T} 2 \mathrm{DM}$, as the incidence of obesity and metabolic syndrome has increased. Previous study showed that in the non-diabetic state and in subjects with impaired glucose tolerance, circulating endogenous free fatty acids (FFAs) are not independently associated measures of $\beta$-cell function, and do not predict deterioration of glucose tolerance [5]. Interestingly, many studies have found that FFAs are involved in the development of insulin resistance. When the level of FFAs in the blood increases, the excessive supply of FFAs and lipids exceeds adipose tissue adaptation, causing adipocyte insulin resistance and lipid accumulation in non-adipose tissues, such as the liver, muscle and pancreatic $\beta$ cells as well as around the heart, and causing systemic or local dysfunction [6]. It has been reported that ectopic fat deposition, such as lipid deposition in the liver, can increase peripheral insulin resistance [7- 10]. There are clear methods, such as liver enzyme tests, magnetic resonance imaging (MRI), and quantitative computed tomography (QCT), that can be used to evaluate the degree of liver fat deposition. However, the effects of pancreatic tissue fat deposition on metabolism, insulin resistance and islet cell function have yet to be clearly investigated.

Schaefer first described pancreatic fat infiltration and reported the relationship between human body weight and pancreatic fat content in 1926 [11]. In 1933, Ogilvie autopsied 19 deceased patients and found differences in their pancreatic exocrine glands. The degree of fat increase, the predominant prevalence of obesity and the difference in pancreatic fat content between obese and non-obese individuals led to the development of the concept of "pancreatic lipomatosis" [12]. Catanzaro $\mathrm{R}$ et al. proposed the concept of non-alcoholic fatty pancreas disease (NAFPD) in 2016 [13]. The role of pancreatic steatosis in the pathogenesis of T2DM is currently under discussion, as different views have emerged. It is unclear whether lipid accumulation in the pancreas contributes to $\beta$-cell dysfunction because to date, no effective enzymology or imaging method has been found that can easily and accurately assess pancreatic fat deposition.

Imaging studies are expected to produce reliable information regarding the amount and content of visceral fat. Indeed, QCT and MRI can accurately calculate the area and volume of intra-abdominal fat and are currently recognized as the gold standard for assessing adipose tissue distribution in the subcutaneous and abdominal areas [14]. Hepatic and pancreatic fat content can be detected by proton magnetic resonance spectroscopy [15], computed tomography (CT) [16], and MRI [17, 18]. However, MRI is not routinely used because it is time consuming and very expensive. QCT is corrected with a template, and the accuracy of the measurement is high. The measurement of fat is intuitive and accurate, and the accuracy of measuring abdominal fat with QCT is similar to that of MRI. There have been more studies on liver fat deposition [19-21] and fewer on the measurement of pancreatic fat deposition by QCT [22]. We are interested in whether QCT can be used as an economical, efficient and accurate research tool to assess the extent of pancreatic fat deposition and its relationship to islet $\beta$-cell function.

The present study was designed to analyse the correlation between fat deposition in two organs and islet cell function in patients with newly diagnosed T2DM by quantifying the fat content of the liver and pancreas with QCT to determine the associations and clinical significance.

\section{Methods}

\section{Study population}

This study was carried out during the period from Feb 2016 to Jan 2019 at the Endocrinology Department of Xuzhou Central Hospital. A total of 106 subjects with newly diagnosed T2DM included 45 females and 61 males were selected. Ethics approval was obtained from the Ethical Committees of Xuzhou Central Hospital, and the study was conducted in accordance with the principles of the Declaration of Helsinki. Written informed consent was obtained from all participants.

The diagnostic criteria for diabetes were based on the 2014 American Diabetes Association (ADA) criteria. Patients with new-onset T2DM had a plasma fasting glucose level $>7.0 \mathrm{mmol} / \mathrm{L}$ or $2 \mathrm{~h}$ oral glucose tolerance test (OGTT) values $>11.1 \mathrm{mmol} / \mathrm{L}$ without a previous diabetes diagnosis.

Subjects were excluded from this study if they had any of the following conditions: (1) hepatic or pancreatic disease, including inflammation, tumour, or autoimmune disease; (2) other malignant tumours; (3) acute complications of diabetes, including diabetic hyperosmolar coma, ketoacidosis, lactic acidosis, or hypoglycaemic coma; (4) active or chronic infection or inflammatory disease; (5) severe liver and kidney dysfunction; (6) use of medicine that affects blood or urine glucose levels; (7) acute cardio-cerebral vascular accident; or (8) pregnancy. 


\section{Anthropometric measurements}

Height and weight were measured by trained nurses with standardized and calibrated scales and stadiometers. Body mass index (BMI) was calculated with Microsoft Excel as weight in kilograms divided by the square of the height in metres. Waist circumference (WC) was measured midway between the superior border of the iliac crest and the lowest rib. Neck circumference (NC) was measured in the thinnest part of the neck below the throat. Systolic and diastolic blood pressures (SBP and DBP) were measured by trained nurses using a standard mercury sphygmomanometer after the subject had rested for at least $5 \mathrm{~min}$. After an overnight 12-h fast, all subjects underwent routine biochemistry testing, including glycosylated haemoglobin (HbA1c), total cholesterol (TC), triglyceride (TG), high-density lipoprotein (HDL) and low-density lipoprotein (LDL).

\section{Beta cell function and insulin resistance}

To estimate $\beta$-cell function (BCF) and insulin resistance (IR), several indices were used. A total of 106 subjects underwent a 2-h, 75-g OGTT during a screening visit. Serum insulin, C-peptide and plasma glucose levels were measured at every time point with blood samples drawn at 0,30, 60 and 120 min after the subjects consumed the glucose. The areas under the curves (AUC), which were calculated using the trapezoid rule, for glucose and insulin were used to represent the total secretory response over the entire OGTT period. The modified $\beta$-cell function index (MBCI) was calculated as follows: (Fasting insulin (Fins) $\times$ fasting plasma glucose $(\mathrm{FPG})) /(120 \mathrm{~min}$ plasma glucose (Glucose $120 \mathrm{~min})+60 \mathrm{~min}$ plasma glucose (Glucose $60 \mathrm{~min})-2 \mathrm{FPG}$ ) [23]. IR was assessed by the Homeostatic Model Assessment of Insulin

Resistance (HOMA-IR) (HOMA-IR $=($ Fins $\times F P G) /$ 22.5). The insulin secretion index: Homeostatic Model Assessment $\beta$ (HOMA- $\beta$ ) was calculated as $20 \times$ fasting C-peptide (FCP)/(FPG-3.5). $\Delta \mathrm{I} / \Delta \mathrm{G}$ was calculated as the insulin increase at $30 \mathrm{~min}$ above the basal level divided by the corresponding glucose increase (Ins $30 \mathrm{~min}$-Fins)/(Glucose $30 \mathrm{~min}$ - FPG).

\section{Quantitative computed tomography}

The subjects underwent routine CT scanning of the upper abdomen using a scanner (GE OPTIMA 680) with a QCT phantom (Mindways, Austin, TX, USA). The scanning parameters were as follows: tube current, $250 \mathrm{~mA}$; tube voltage, $120 \mathrm{kvp}$; and section thickness, $1 \mathrm{~mm}$. The CT scanning information was transmitted to the QCT Pro 3D spine module software workstation. For quantitative measurement of pancreatic fat, two experienced radiologists independently placed three round regions of interest (ROIs) manually in the pancreatic head, body, and tail in different QCT sections. Care was taken to not include intra-pancreatic vessels and pancreatic ducts. Each of the three ROIs had an area of approximately $100-150 \mathrm{~mm}^{2}$ (Figure 1A). For quantitative measurement of hepatic fat, ROIs were placed on the section at which the right branch of the portal vein enters the liver. Three circular ROIs covering an area of approximately $290 \mathrm{~mm}^{2}$ were drawn into the left lobe, the right anterior lobe and the right posterior lobe. Obvious blood vessels and bile ducts were avoided (Figure 1B). Using the export function of the QCT Pro software database, the field uniformity correction (FUC), the bone mineral density (BMD) value of three measurements and the corresponding calibration slope were derived.

B
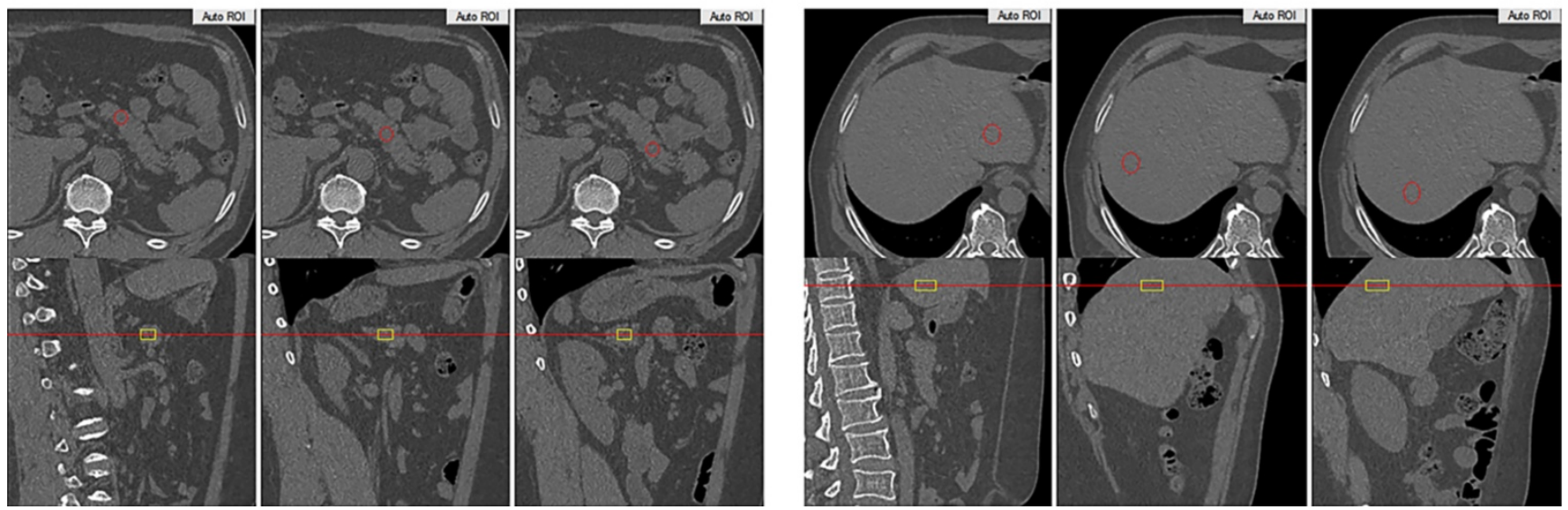

Figure 1. QCT measurement of pancreatic and liver fat content. A: Head, body and tail of the pancreas to measure pancreatic fat content. B: Left lobe, anterior segment of the right lobe and the posterior segment of the right lobe of the liver to measure liver fat content. 
Table 1. Clinical and biochemical characteristics of new-onset T2DM according to estimated pancreatic fat tertiles

\begin{tabular}{|c|c|c|c|c|}
\hline & Estimated pancreas & & & \\
\hline Variables & T1 & $\mathrm{T} 2$ & T3 & $\mathrm{P}$ for trend \\
\hline Age (years) & $41.69 \pm 14.93$ & $47.85 \pm 10.49$ & $48.05 \pm 12.86$ & 0.031 \\
\hline $\mathrm{WC}(\mathrm{cm})$ & $102.48 \pm 17.21$ & $93.06 \pm 10.98$ & $95.30 \pm 7.93$ & 0.123 \\
\hline $\mathrm{NC}(\mathrm{cm})$ & $41.43 \pm 5.29$ & $36.32 \pm 3.63$ & $38.70 \pm 3.06$ & 0.063 \\
\hline BMI $\left(\mathrm{kg} / \mathrm{m}^{2}\right)$ & $28.52 \pm 6.81$ & $26.55 \pm 5.76$ & $27.16 \pm 5.23$ & 0.325 \\
\hline SBP (mmHg) & $134.03 \pm 9.81$ & $131.79 \pm 13.18$ & $128.16 \pm 13.77$ & 0.774 \\
\hline DBP (mmHg) & $79.85 \pm 8.69$ & $82.92 \pm 8.61$ & $79.30 \pm 8.11$ & 0.135 \\
\hline${ }^{*}$ Fins $(\mu \mathrm{IU} / \mathrm{mL})$ & $8.3(5.46 \sim 13.47)$ & 7.91 (5.40 12.24) & $7.11(3.80 \sim 14.19)$ & 0.964 \\
\hline${ }^{*} \operatorname{Ins}_{30 \min }(\mu \mathrm{IU} / \mathrm{mL})$ & 16.65 (11.50 34.51) & $21.26(8.79 \sim 27.85)$ & $13.06(7.34 \sim 34.60)$ & 0.484 \\
\hline${ }^{*} \operatorname{Ins}_{60 \min }(\mu \mathrm{IU} / \mathrm{mL})$ & 26.91 (14.50 49.71) & 30.27 (17.22 49.05) & $17.83(10.49 \sim 58.08)$ & 0.289 \\
\hline${ }^{*} \operatorname{Ins}_{120 \min }(\mu \mathrm{IU} / \mathrm{mL})$ & 25.14 (18.10 48.63) & $31.72(15.30 \sim 41.02)$ & $23.26(10.59 \sim 58.63)$ & 0.973 \\
\hline $\mathrm{FCP}(\mathrm{ng} / \mathrm{mL})$ & $3.02 \pm 1.83$ & $2.51 \pm 1.25$ & $2.83 \pm 1.26$ & 0.166 \\
\hline $\mathrm{CP}_{30 \min }(\mathrm{ng} / \mathrm{mL})$ & $4.12 \pm 2.21$ & $4.09 \pm 3.69$ & $3.63 \pm 2.35$ & 0.728 \\
\hline $\mathrm{CP}_{60 \min }(\mathrm{ng} / \mathrm{mL})$ & $5.32 \pm 2.93$ & $5.70 \pm 4.04$ & $4.73 \pm 3.08$ & 0.899 \\
\hline $\mathrm{CP}_{120 \min }(\mathrm{ng} / \mathrm{mL})$ & $6.23 \pm 3.79$ & $7.15 \pm 6.38$ & $6.59 \pm 3.68$ & 0.439 \\
\hline $\mathrm{FPG}(\mathrm{mmol} / \mathrm{L})$ & $10.82 \pm 3.87$ & $9.70 \pm 3.87$ & $10.02 \pm 3.27$ & 0.329 \\
\hline Glucose $_{30 \min }(\mathrm{mmol} / \mathrm{L})$ & $13.97 \pm 3.73$ & $13.75 \pm 4.38$ & $14.80 \pm 4.28$ & 0.464 \\
\hline Glucose $_{60 \min }(\mathrm{mmol} / \mathrm{L})$ & $17.63 \pm 3.70$ & $17.20 \pm 5.18$ & $18.31 \pm 4.66$ & 0.413 \\
\hline $\operatorname{Glucose}_{120 \min }(\mathrm{mmol} / \mathrm{L})$ & $17.82 \pm 5.85$ & $16.46 \pm 6.28$ & $18.98 \pm 5.36$ & 0.097 \\
\hline HbA1c (\%) & $10.65 \pm 3.10$ & $9.14 \pm 2.67$ & $10.12 \pm 2.67$ & 0.842 \\
\hline $\mathrm{TC}(\mathrm{mmol} / \mathrm{L})$ & $4.82 \pm 1.32$ & $5.03 \pm 0.98$ & $5.16 \pm 0.97$ & 0.043 \\
\hline $\mathrm{TG}(\mathrm{mmol} / \mathrm{L})$ & $2.70 \pm 2.11$ & $2.43 \pm 1.38$ & $2.87 \pm 2.42$ & 0.737 \\
\hline $\mathrm{HDL}$ (mmol/L) & $1.05 \pm 0.24$ & $1.09 \pm 0.21$ & $1.01 \pm 0.18$ & 0.139 \\
\hline $\mathrm{LDL}$ (mmol/L) & $3.04 \pm 0.92$ & $3.22 \pm 0.70$ & $3.32 \pm 0.88$ & 0.823 \\
\hline
\end{tabular}

Data are shown as medians (interquartile range) or means \pm standard deviations depending on the data distribution. WC, waist circumference; $\mathrm{NC}$, neck circumference; $\mathrm{BMI}$ body mass index; SBP, systolic blood pressure; DBP, diastolic blood pressure; Fins, fasting insulin; Ins30min, 30 min insulin; Ins60min, 60 min insulin; Ins120min, 120 min insulin; $\mathrm{FCP}$, fasting C-peptide; $\mathrm{CP}_{30 \mathrm{~min}}, 30 \mathrm{~min} \mathrm{C}$-peptide; $\mathrm{CP}_{60 \mathrm{~min}}, 60 \mathrm{~min} \mathrm{C}$-peptide; $\mathrm{CP}_{120 \mathrm{~min}}, 120 \mathrm{~min}$ C-peptide; FPG, fasting plasma glucose; Glucose $30 \mathrm{~min}$, 30 min plasma glucose; Glucose $60 \mathrm{~min}, 60 \mathrm{~min}$ plasma glucose; Glucose $120 \mathrm{~min}, 120 \mathrm{~min}$ plasma glucose; HbA1c, glycosylated haemoglobin; TC, total cholesterol; TG, triglyceride; HDL, high-density lipoprotein; LDL, low-density lipoprotein.

QCT measurements of hepatic or pancreatic tissue using the Mindways spine module software were converted into percentage fat measurements using a published method for measuring liver fat and pancreatic fat by Cheng $X$ et al. and calculated using the following equation [20-22]:

$$
\begin{gathered}
\% \text { fat }_{\text {pancreas }}=\left(\frac{H u_{\text {leanpancreas }}-H u_{\text {pancreas }}}{H u_{\text {leanpancreas }}-H u_{\text {fat }}}\right) \times 100 \% \\
\% \text { fat }_{\text {liver }}=\left(\frac{H u_{\text {leanliver }}-H u_{\text {liver }}}{H u_{\text {leanliver }}-H u_{\text {fat }}}\right) \times 100 \%
\end{gathered}
$$

where $\mathrm{HU}_{\text {pancreas }}$ and $\mathrm{HU}_{\text {liver }}$ are the radiodensity measurements in the pancreatic and hepatic ROIs, and the values were found by converting the BMD measurements from the Mindways scan analysis software to radiodensity values using the QCT Pro scan calibration data. $\mathrm{HU}_{\mathrm{fat}}$ and $\mathrm{HU}_{\text {leanliver }}$ and $\mathrm{HU}_{\text {leanpancreas }}$ are the radiodensity values for $100 \%$ fat and fat-free hepatic tissue and fat-free pancreatic tissue, respectively, and their values were found by representing fat and fat-free tissue in terms of their basis set equivalent densities of water $(\mathrm{H} 2 \mathrm{O})$ and dipotassium hydrogen phosphate (K2HPO4) and adjusting for tube voltage and person-to-person differences in beam hardening using scan calibration data from the QCT Pro software.

\section{Statistical analysis}

All subjects were categorized into trisections of estimated pancreas fat and liver fat (T1, T2, T3). The data are presented as medians (interquartile range) or means \pm standard deviations depending on the data distribution. We used ANOVA to explore the differences between groups. Correlations of estimated pancreas fat and liver fat with clinical parameters reflecting islet function or insulin resistance were assessed with Pearson's correlation, and those correlations were adjusted for sex, age, BMI (and HOMA-IR or WC) using partial correlation. Linear regression analysis was performed to show the correlation between islet function and estimated liver fat. The trend of $\mathrm{AUC}_{\mathrm{INS}}$ and HOMA-IR changing with estimated pancreas fat or/and liver fat was shown using scatter plots. $P$ values less than 0.05 were considered significant. SPSS statistical software version 22.0 was used for data management and statistical analyses.

\section{Results}

\section{Comparison of new-onset T2DM characteristics according to estimated pancreas fat}

A total of 106 subjects included 45 females and 61 males participated in the study. The baseline characteristics of the study subjects according to estimated pancreas fat tertiles are presented in Table 1. As the estimated pancreas fat tertile increased, 
patients were more likely to be older. The serum TC content increased across the estimated pancreas fat tertiles $(P$ for trend $<0.05)$. There was no significant trend or no trend of increase or decrease between estimated pancreas fat tertiles and WC, NC, BMI, SBP, DBP, serum insulin, C-peptide, plasma glucose, TG, HDL, LDL, HbA1c.

\section{Comparison of new-onset T2DM characteristics according to estimated liver fat}

The baseline characteristics of the study subjects according to estimated liver fat tertiles are presented in Table 2. As the estimated liver fat tertile increased, patients were more likely to be younger. BMI ( $P$ for trend $=0.03$ ), Fins ( $P$ for trend $=0.003$ ), 120-min insulin (Ins120min) ( $P$ for trend=0.006), and FCP $(P$ for trend $=0.004$ ) levels increased across estimated liver fat tertiles. There was a trend of increase between estimated liver fat tertiles and WC or NC, but this trend was not statistically significant. We could not find increasing or decreasing linear relationships between estimated liver fat tertiles and blood lipids.

\section{Estimated pancreas fat or liver fat and BCF}

AUC INS $_{\text {IN }}(r=0.237, P=0.021), \quad \mathrm{MBCI} \quad(r=0.297$, $P=0.004)$, and HOMA- $\beta \quad(r=0.267, P=0.006)$ were positively correlated with estimated liver fat in the Pearson correlation analysis. However, all correlations lost significance for estimated pancreas fat (Table 3). Linear regression analysis indicated that HOMA- $\beta \quad(P=0.014), \mathrm{AUC}_{\mathrm{INS}}(P=0.032)$, and $\mathrm{MBCI}$ $(P=0.024)$ remained significantly associated with estimated liver fat (Table 4). Furthermore, AUC $\mathrm{INS}_{\mathrm{IN}}$ was associated with estimated liver fat in the partial correlation analysis $(r=0.271, P=0.008)$. We could not find a significant correlation between estimated pancreas fat and $\mathrm{AUC}_{\mathrm{INS}}$ after adjustment for sex, age and BMI (Figure 2A). No significant correlations existed between AUC for glucose or $\Delta \mathrm{I} / \Delta \mathrm{G}$ and estimated pancreas fat or liver fat in the Pearson correlation analysis (Table 3 ). The results regarding estimated liver fat and $\mathrm{AUC}_{\mathrm{INS}}$ and HOMA- $\beta$ remained significant after accounting for sex, age, BMI and HOMA-IR (or WC) (Supplementary Table 1, Supplementary Table 2).

\section{Estimated pancreas fat or liver fat and IR}

IR as calculated by the HOMA-IR was positively correlated with estimated liver fat in the Pearson correlation analysis $(r=0.311, P=0.001)$ (Table 3). Moreover, partial correlation analysis between estimated liver fat and HOMA-IR showed a correlation coefficient of $r=0.278(P=0.004)$ (Figure 2B). No significant correlations were found between estimated pancreas fat and HOMA-IR in either the Pearson or partial correlation analysis (Table 3, Figure 2B).

Table 2. Clinical and biochemical characteristics of new-onset T2DM according to estimated liver fat tertiles

\begin{tabular}{|c|c|c|c|c|}
\hline & Estimated liver fat & & & \\
\hline Variables & $\mathrm{T} 1$ & $\mathrm{~T} 2$ & $\mathrm{~T} 3$ & $P$ for trend \\
\hline Age (years) & $50.33 \pm 11.82$ & $47.28 \pm 12.51$ & $39.68 \pm 13.13$ & $<0.001$ \\
\hline $\mathrm{WC}(\mathrm{cm})$ & $93.76 \pm 7.42$ & $97.52 \pm 15.47$ & $100.78 \pm 15.18$ & 0.107 \\
\hline $\mathrm{NC}(\mathrm{cm})$ & $37.90 \pm 3.34$ & $38.86 \pm 5.42$ & $40.43 \pm 4.66$ & 0.09 \\
\hline BMI $\left(\mathrm{kg} / \mathrm{m}^{2}\right)$ & $26.17 \pm 5.40$ & $26.99 \pm 7.07$ & $29.19 \pm 4.99$ & 0.03 \\
\hline SBP (mmHg) & $130.74 \pm 11.68$ & $133.32 \pm 14.96$ & $130.11 \pm 10.63$ & 0.826 \\
\hline DBP (mmHg) & $79.64 \pm 8.40$ & $82.00 \pm 7.98$ & $80.27 \pm 9.31$ & 0.750 \\
\hline${ }^{*}$ Fins $(\mu \mathrm{IU} / \mathrm{mL})$ & 6.47 (3.78 10.71) & $7.07(4.09 \sim 12.40)$ & $10.73(7.05 \sim 14.73)$ & 0.003 \\
\hline${ }^{*} \operatorname{Ins} 30 \min (\mu \mathrm{IU} / \mathrm{mL})$ & $15.93(8.08 \sim 23.86)$ & $13.80(8.36 \sim 28.86)$ & $21.80(11.69 \sim 37.05)$ & 0.127 \\
\hline${ }^{*} \operatorname{Ins}_{60 \min }(\mu \mathrm{IU} / \mathrm{mL})$ & 19.79 (11.66 38.46) & $23.51(10.91 \sim 36.26)$ & $32.17(15.94 \sim 63.22)$ & 0.158 \\
\hline${ }^{*} \operatorname{Ins}_{120 \min }(\mu \mathrm{IU} / \mathrm{mL})$ & $19.77(13.09 \sim 33.30)$ & $24.00(14.92 \sim 43.32)$ & $41.32(18.76 \sim 68.35)$ & 0.006 \\
\hline $\mathrm{FCP}(\mathrm{ng} / \mathrm{mL})$ & $2.31 \pm 1.35$ & $2.70 \pm 1.59$ & $3.32 \pm 1.31$ & 0.004 \\
\hline $\mathrm{CP}_{30 \min }(\mathrm{ng} / \mathrm{mL})$ & $3.69 \pm 3.82$ & $3.69 \pm 2.52$ & $4.47 \pm 1.85$ & 0.281 \\
\hline $\mathrm{CP}_{60 \min }(\mathrm{ng} / \mathrm{mL})$ & $4.65 \pm 4.09$ & $5.25 \pm 3.49$ & $5.79 \pm 2.57$ & 0.194 \\
\hline $\mathrm{CP}_{120 \min }(\mathrm{ng} / \mathrm{mL})$ & $5.67 \pm 6.40$ & $6.76 \pm 3.97$ & $7.44 \pm 3.40$ & 0.114 \\
\hline $\mathrm{FPG}(\mathrm{mmol} / \mathrm{L})$ & $10.57 \pm 3.56$ & $10.17 \pm 4.05$ & $9.91 \pm 3.42$ & 0.445 \\
\hline Glucose $30 \min (\mathrm{mmol} / \mathrm{L})$ & $14.80 \pm 3.75$ & $13.99 \pm 4.83$ & $13.81 \pm 3.78$ & 0.341 \\
\hline Glucose $60 \min (\mathrm{mmol} / \mathrm{L})$ & $18.24 \pm 4.52$ & $17.25 \pm 5.18$ & $17.73 \pm 4.01$ & 0.661 \\
\hline $\operatorname{Glucose}_{120 \min }(\mathrm{mmol} / \mathrm{L})$ & $18.14 \pm 6.07$ & $17.26 \pm 6.48$ & $17.90 \pm 5.18$ & 0.866 \\
\hline $\operatorname{HbA} 1 \mathrm{c}(\%)$ & $10.67 \pm 2.99$ & $9.72 \pm 3.01$ & $9.73 \pm 2.55$ & 0.177 \\
\hline $\mathrm{TC}(\mathrm{mmol} / \mathrm{L})$ & $5.03 \pm 1.11$ & $4.98 \pm 1.19$ & $5.02 \pm 1.02$ & 0.978 \\
\hline TG (mmol/L) & $2.63 \pm 2.05$ & $2.17 \pm 1.20$ & $3.24 \pm 2.50$ & 0.191 \\
\hline HDL (mmol/L) & $1.06 \pm 0.19$ & $1.09 \pm 0.25$ & $1.01 \pm 0.21$ & 0.321 \\
\hline LDL (mmol/L) & $3.15 \pm 0.81$ & $3.28 \pm 0.92$ & $3.16 \pm 0.81$ & 0.955 \\
\hline
\end{tabular}

Data are shown as medians (interquartile range) or means \pm standard deviations depending on the data distribution. WC, waist circumference; $\mathrm{NC}$, neck circumference; $\mathrm{BMI}$ body mass index; SBP, systolic blood pressure; DBP, diastolic blood pressure; Fins, fasting insulin; Ins $30 \mathrm{~min}, 30 \mathrm{~min}$ insulin; Ins $60 \mathrm{~min}$, 60 min insulin; Ins $120 \mathrm{~min}$, 120 min insulin; FCP, fasting C-peptide; $\mathrm{CP}_{30 \mathrm{~min}}, 30 \mathrm{~min} \mathrm{C}$-peptide; $\mathrm{CP}_{60 \mathrm{~min}}, 60 \mathrm{~min} \mathrm{C}$-peptide; $\mathrm{CP}_{120 \mathrm{~min}}, 120 \mathrm{~min} \mathrm{C}$-peptide; FPG, fasting plasma glucose; Glucose $30 \mathrm{~min}$, 30 min plasma glucose; Glucose $_{60 \mathrm{~min}}, 60 \mathrm{~min}$ plasma glucose; Glucose $120 \mathrm{~min}, 120 \mathrm{~min}$ plasma glucose; HbA1c, glycosylated haemoglobin; TC, total cholesterol; TG, triglyceride; HDL, high-density lipoprotein; LDL, low-density lipoprotein. 
A

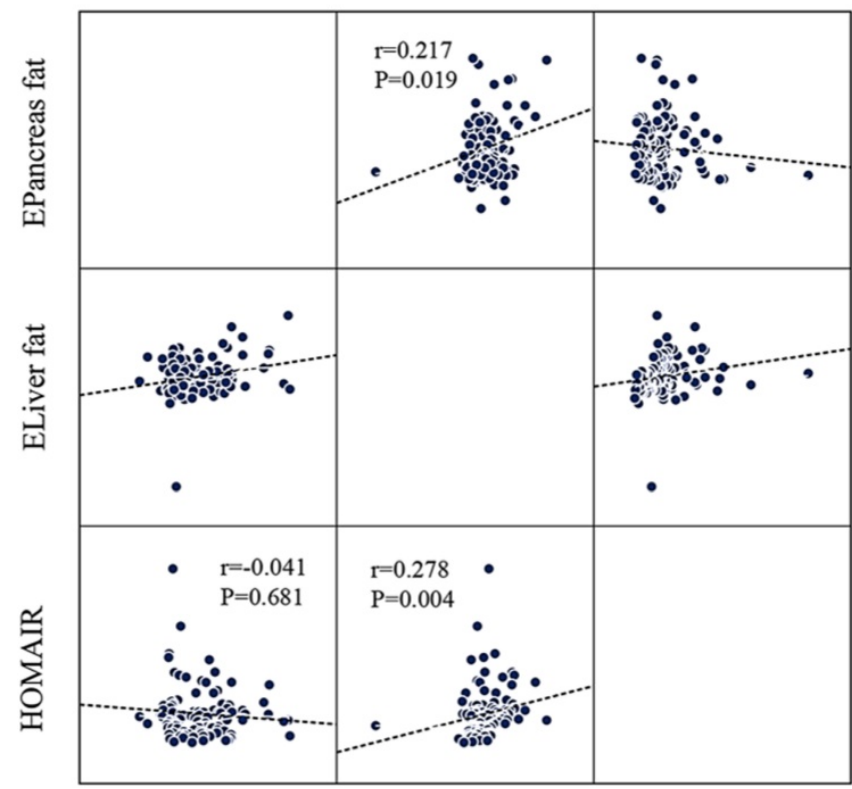

EPancreas fat

ELiver fat

HOMAIR
B

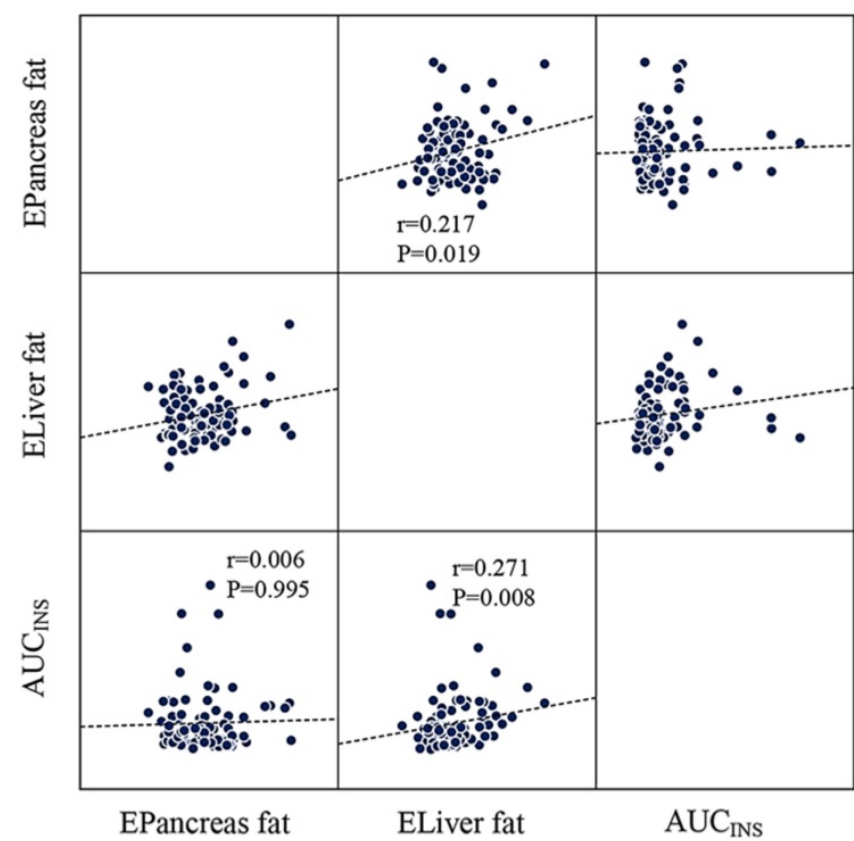

Figure 2. The scatter plots showing the correlation between HOMA-IR, AUC INs and estimated pancreas fat or liver fat with the result of partial correlation analysis (controlling for sex, age and BMI). A: Estimated liver fat was positively correlated with HOMA-IR $(r=0.278, P=0.004)$. No significant correlation was found between estimated pancreatic fat and HOMA-IR $(P=0.681)$. B: Negative correlation of estimated liver fat with $A U C_{\mid N S}(r=0.271, P=0.008)$ and is significant compared to estimated pancreatic fat. ( $\left.P=0.995\right)$. $A$ positive correlation was found between estimated pancreatic fat and estimated liver fat $(r=0.217, P=0.019)$.

Table 3. Pearson correlation analysis between estimated pancreas fat or liver fat and clinical parameters reflecting islet function or insulin resistance

\begin{tabular}{lllll}
\hline & \multicolumn{2}{l}{ Estimated pancreas fat by QCT } & \multicolumn{2}{l}{ Estimated liver fat by QCT } \\
\hline Variables & $\mathrm{r}$ & $\mathrm{P}$ & $\mathrm{r}$ & $\mathrm{P}$ \\
HOMA-IR & -0.033 & 0.738 & 0.311 & 0.001 \\
AUC $_{\mathrm{PG}}$ & 0.031 & 0.765 & -0.014 & 0.893 \\
AUC $_{\mathrm{INS}}$ & -0.045 & 0.664 & 0.237 & 0.021 \\
$\mathrm{MBCI}$ & -0.131 & 0.217 & 0.297 & 0.004 \\
$\Delta \mathrm{I} / \Delta \mathrm{G}$ & -0.137 & 0.194 & 0.173 & 0.101 \\
HOMA- $\beta$ & 0.020 & 0.836 & 0.267 & 0.006 \\
\hline
\end{tabular}

HOMA-IR, Homeostatic Model Assessment of Insulin Resistance; AUCPG, AUC for plasma glucose; AUCINs, AUC for insulin; MBCI, modified $\beta$-cell function index; I, insulin; G, glucose; HOMA- $\beta$, homeostatic model assessment $\beta$.

Table 4. Linear regression analysis between estimated liver fat and islet function

\begin{tabular}{lllll}
\hline & Beta & $95 \% \mathrm{CI}$ & $\mathrm{t}$ & $\mathrm{P}$ \\
\hline $\mathrm{Y}=$ HOMA- $\beta$ & 0.016 & $0.003 \sim 0.029$ & 2.503 & 0.014 \\
Y=AUC INS & 0.012 & $0.001 \sim 0.023$ & 2.18 & 0.032 \\
Y=MBCI & 0.012 & $0.002 \sim 0.022$ & 2.301 & 0.024 \\
\hline
\end{tabular}

HOMA- $\beta$, homeostatic model assessment $\beta$; $\mathrm{AUC}_{\mathrm{INS}}$, AUC for insulin; $\mathrm{MBCI}$, modified $\beta$-cell function index; $\mathrm{CI}$, confidence interval.

\section{Others}

In the whole cohort, a positive correlation was found between estimated pancreas fat and estimated liver fat in the partial correlation analysis $(r=0.217$, $P=0.019$ ) (Figure 2B).

\section{Discussion}

The present study analysed the association between fat deposition in the pancreas and islet cell function in patients with newly diagnosed T2DM by quantifying the fat in the pancreas using QCT. First, significant differences could be found in the estimated liver fat as well as in parameters of the BCF and IR. However, our study also provided an interesting perspective, showing that pancreatic fat in particular did not influence islet cell function in newly diagnosed T2DM patients. To the best of our knowledge, this is the first report to show the correlation of islet cell function and pancreatic fat deposition using QCT.

The excessive accumulation of fat in non-adipose tissues is a reported risk factor for IR in liver and skeletal muscle, contributing to the development and progression of diabetes [24-27]. A theory has been proposed in which excess FFAs from the highly insulin-resistant visceral adipose tissue (VAT) spill into the liver, leading to excess hepatic adiposity and increased insulin resistance [28]. Fat deposition in liver tissue leads to a decrease in the ability of insulin to suppress the production of glucose and the level of VLDL [29, 30]. As the understanding of the mechanism of fat spill-over deepens, another theory proposed that increased intrahepatic lipid accumulation leads to increased export of VLDL- 
triglycerides from the liver, which subsequently deposit in the pancreas, contributing to $\beta$-cell failure [31]. Fat deposition in the pancreas causes local chronic low-grade inflammation leading to islet cell inflammation and dysfunction [32- 34]. Fat deposition in the pancreas could potentially have a destructive influence on insulin-producing $\beta$ cells, both directly through lipotoxic mechanisms mediated by the release of FFAs and indirectly through the activation of inflammatory pathways $[35,36]$.

Given the interest in the role of excessive pancreatic fat deposition in the pathogenesis of T2DM, there have been few previous studies on the relationship between pancreatic fat and pancreatic endocrine function. One study found that pancreatic fat was a stronger determinant of impaired insulin secretion in subjects with prediabetes [37]. Lu et al. found that pancreatic fat content is associated with $\beta$-cell function in Chinese T2DM subjects [38]. Tushuizen et al. also concluded that the pancreatic fat content was inversely associated with $\beta$-cell function in nondiabetic subjects [39]. In contrast, some studies have found no association of NAFPD with $\beta$-cell function. Researchers from Hong Kong used MRI as a research tool to confirm the lack of a significant correlation between NAFPD and $\beta$-cell function after adjusting for hepatic fat content and BMI [40]. Similar findings were also obtained in another study in which research could not establish an association between pancreatic fat content and $\beta$-cell function in individuals with impaired glucose metabolism [41]. Wicklow et al. also found that pancreatic triglyceride content, as measured by magnetic resonance spectroscopy (MRS), is not associated with $\beta$-cell function in youth with new-onset T2DM [42].

The results we obtained using QCT as a research tool were consistent with the latter study mentioned above. Our study showed that significant differences could be found in estimated liver fat as well as in the parameters of the BCF and IR. HOMA-IR was positively correlated with estimated liver fat. Interestingly, a positive correlation was found regarding estimated liver fat and $\mathrm{AUC}_{\mathrm{INS}}, \mathrm{MBCI}$, and HOMA- $\beta$. However, we could not establish a relationship between pancreatic fat content and $\beta$-cell function. These previous findings and our concurring data lead us to conclude that pancreatic fat is not associated with BCF in individuals with prediabetes and new-onset T2DM [41, 42]. This provides us with more insight into the pathogenesis of T2DM, which is characterized by insulin resistance and $\beta$-cell dysfunction. There are two phenomena, glucotoxicity and lipotoxicity, which have been postulated to harm $\beta$ cells [43]. Subsequently, the term "glucolipotoxicity" was coined in recognition of the interrelationship between glucotoxicity and lipotoxicity [43, 44]. Many findings support the hypothesis that glucotoxicity is a necessary initial condition of lipotoxicity [45, 46]. Long-term lipotoxicity has a more important effect on the inhibition of insulin release [47]. The deleterious effect of pancreatic fat on $\beta$ cells may be permissive to hyperglycaemia in the early stages of T2DM. The deposits of fat in the pancreas and the resulting lipotoxicity may play an important role in the late stage of islet cell dysfunction as the course of T2DM progresses. The influence of glucotoxicity and lipotoxicity on $\beta$-cell function and their effects on the pathogenesis of T2DM remain to be further explored.

The association of pancreatic fat and $\beta$-cell function was not found in new-onset T2DM. This may be explained by pathophysiological factors, which are more likely to account for the findings. It has been theorized that once T2DM occurs, the effect of other factors superimposing pancreatic steatosis may account for the gradual decline in $\beta$-cell function. That is, due to many deleterious cascades, including inflammation, oxidative stress, apoptosis and hypoperfusion of islets, the rate of deterioration of $\beta$-cell function is not disproportionate to pancreatic fat accumulation [39]. Additionally, we cannot discriminate between intra- and inter-islet fat accumulations. There may be different mechanisms for the effects of pancreatic exocrine tissue fat deposition and pancreatic islet cell fat deposition on pancreatic islet function. Our observation was found only at the onset of T2DM in individuals and not in other stages of T2DM. Our results support this hypothesis: fat deposits in the liver, an important organ involved in lipid metabolism, play a primary role in IR in early diabetes. The role of the pancreas may be due to the specificity of the tissue structure (there is no specific cell that can store a large amount of fat), and the effect of pancreatic fat deposition on islet cell function cannot be equal to the effect of liver fat deposition on islet cell function.

Abnormal accumulation of fat in hepatocytes cause fatty liver has been clear, but the deposition of fat in the pancreas is currently unclear. Recent studies have found only that fat deposition in pancreatic tissue occurs mostly between lobules $[48,49]$ or that triglycerides are found inside islet cell sediment [50]. The development and functional effects of pancreatic fat deposition are still in the exploration stage. Our team has also made some meagre efforts in the research direction of the mechanism of pancreatic fat deposition. We paid more attention to the pathophysiological mechanism of fat deposition inside the islet because its effect on islet function may exceed the role of fat deposition in pancreatic exocrine tissue. 
Our previous studies have confirmed the presence of stellate cells within the islets (ISCs), which are identical in the expression of retinoid-containing fat droplets [51, 52, 53, 54,55]. A loss of oil red O-stained fat droplets was associated with the activation of diabetic ISCs, and we speculate whether the transfer of lipid droplets from the inside to the outside of the ISCs leads to local fat deposition and the inhibition of normal $\beta$-cell function. We are looking for a process of fat droplet metabolism in ISCs, hoping to find a specific target cell for pancreatic fat deposition studies. The stellate cells present in pancreatic exocrine tissues exhibit biological behaviour similar to that in pancreatic islet stellate cells in fat droplet metabolism. We speculate that pancreatic stellate cells (PSCs) may be the target cell for fat deposition in pancreatic exocrine tissues.

Other studies have found striking ethnic differences in the relationship between pancreatic fat and $\beta$-cell dysfunction. An inverse relationship between pancreatic fat and insulin secretion was seen in Hispanic adults with mild obesity rather than in black or white adults [56] and African American minority adolescents with prediabetes rather than Latinos [57]. This discrepancy may be due to the differences in the populations studied and suggests a major influence of ancestral genes. However, our study targeted only a small population with new-onset T2DM in China and concluded that there was no correlation between pancreatic fat and $\beta$-cell function. The harmful effect of pancreatic fat on insulin secretion may be strengthened in persons who are genetically predisposed to develop T2DM. The racial or ethnic genetic difference in ectopic fat is still unknown and requires further exploration.

In addition to pathophysiological and population selection factors, it is possible that methodological factors also influenced our results. Imaging techniques such as ultrasound, MRI and CT can be used to measure regional adipose tissue in vivo $[18,58,59]$. Although MRI is free from radiation, its application is still limited by its high cost and long scanning time. Compared to MRI, CT is convenient and well tolerated by the public. Adipose tissue can be measured quickly and accurately using QCT [60]. Previous studies have reported the application of QCT for the determination of ectopic fat deposition in the liver [20,61]. An animal study showed that both QCT and MRI measurements of goose liver fat were accurate and reliable compared with chemical methods in vitro [19]. However, only one study has been found on the measurement of pancreatic fat by QCT [22], but no studies have explored the relationship between pancreatic fat quantification with QCT and islet $\beta$-cell function. Our present study quantified pancreatic and hepatic fat by QCT. No association between estimated pancreatic fat and islet cell function was found in patients with new-onset T2DM. In addition, we may attribute this to imaging technique. Yao WJ et al. reported that systematic differences between QCT and chemical-shift-encoded magnetic resonance imaging exist, and the result strongly suggests a good correlation between the two measurements [22]. Our results clearly supported that there is no significant correlation between pancreatic fat deposition and $\beta$-cell function in the early stages of T2DM using QCT. The method for assessing pancreatic fat deposition using QCT will be further improved in the subsequent assessments of clinical tests.

Our study had several limitations. In this study, blood glucose was measured at only 4 time points, so the model of glucose-stimulated insulin secretion proposed by Mari et al. [62] could not be established. The use of HOMA- $\beta$ to respond to insulin secretion may affect the results of the experiment. Although various functions to assess $\beta$-cell function and insulin resistance were used, a gold-standard technique such as a clamp study or minimal modelling of intravenous glucose challenge was not used. Furthermore, the evaluation of the fat content was not done with gold-standard methods, and the studied subjects were exposed to the radiation burden. Finally, the sample size was relatively small and further expansion of the sample size, long-term follow-up observation of patients and specialized animal in vivo experiments to determine molecular mechanisms still need further exploration to elucidate further insights into the pathogenesis of pancreatic fat deposition.

Given the above findings, we conclude that ectopic lipid deposition in the liver is related to IR and $\beta$-cell dysfunction. There was no significant correlation between pancreatic fat deposition and $\beta$-cell function in 106 adults with newly diagnosed T2DM. More meaningfully, this is first report to use QCT as a method to evaluate the correlation of islet cell function and pancreatic fat deposition. Long-term research is needed to gain more insight into the contributing role of ectopic fat in the pancreas to the progressive decline in $\beta$-cell function.

\section{Supplementary Material}

Supplementary tables.

http://www.medsci.org/v17p1673s1.pdf

\section{Acknowledgement and declarations}

This work was supported by generous grants from the Natural Science Foundation of Jiangsu Province (BK20171171), the Xuzhou Science and Technology Bureau project (KC16SH110), the 
National Nature Science Foundation of China (NSFC81803908). The author gratefully acknowledges the support of K.C.Wong Education Foundation, Hong Kong.

\section{Ethics approval and consent to participate}

This study was reviewed and approved by the Ethical Committees of Xuzhou Central Hospital. Written informed consent was obtained from all of the participants.

\section{Availability of data and material}

Please contact the corresponding author with data requests.

\section{Authors' Contributions}

All authors have approved the final version of the manuscript. Wei $\mathrm{Xu}$ is responsible for the integrity of the work as a whole. YX Li, YQ Sang, Yan Sun, XK Liu, HF Geng and Min Zha contributed equally to this work.

\section{Competing Interests}

The authors have declared that no competing interest exists.

\section{References}

1. Chen C, Cohrs CM, Stertmann J, Bozsak R, Speier S. Human beta cell mass and function in diabetes: Recent advances in knowledge and technologies to understand disease pathogenesis. Mol Metab. 2017 Jul 8; 6(9): 943-957.

2. Julia M. Dos Santos, Shikha Tewari, Roberta H. Mendes. The Role of Oxidative Stress in the Development of Diabetes Mellitus and Its Complications. Journal of Diabetes Research. 2019; p: 4189813.

3. Esser N, Legrand-Poels S, Piette J, Scheen AJ, Paquot N. Inflammation as a link between obesity, metabolic syndrome and type 2 diabetes. Diabetes Res Clin Pract. 2014; 105(2): 141-50.

4. Peti-Peterdi J, Kang JJ, Toma I. Activation of the renal renin-angiotensin system in diabetes--new concepts. Nephrol Dial Transplant. 2008; 23(10): 3047-9

5. Eleni Rebelos, Marta Seghieri, Andrea Natali, Beverly Balkau, Alain Golay, Pier Marco Piatti, Nebojsa M. Lalic, Markku Laakso, Andrea Mari, Ele Ferrannini. Influence of endogenous NEFA on beta cell function in humans. Diabetologia. 2015; 58(10): 2344-2351.

6. Unger, R. Lipid overload and overflow: metabolic trauma and the metabolic syndrome. Trends in Endocrinology and Metabolism. 2003; 14(9): 398-403.

7. Cusi, K. The Role of Adipose Tissue and Lipotoxicity in the Pathogenesis of Type 2 Diabetes. Current Diabetes Reports. 2010; 10(4): 306-315.

8. Cantley JL, Yoshimura T, Camporez JP, Zhang D, Jornayvaz FR, Kumashiro N, Guebre-Egziabher F, Jurczak MJ, Kahn M, Guigni BA, Serr J, Hankin J, Murphy RC, Cline GW, Bhanot S, Manchem VP, Brown JM, Samuel VT, Shulman GI. CGI-58 knockdown sequesters diacylglycerols in lipid droplets/ER-preventing diacylglycerol-mediated hepatic insulin resistance. Proc Natl Acad Sci U S A. 2013; 110(5): 1869-74

9. Fabbrini, E. and F. Magkos. Hepatic Steatosis as a Marker of Metabolic Dysfunction. Nutrients. 2015; 7(6): 4995-5019.

10. Jornayvaz FR, Birkenfeld AL, Jurczak MJ, Kanda S, Guigni BA, Jiang DC, Zhang D, Lee HY, Samuel VT, Shulman GI. Hepatic insulin resistance in mice with hepatic overexpression of diacylglycerol acyltransferase 2. Proc Natl Acad Sci U S A. 2011; 108(14): 5748-52.

11. Schaefer JH. The normal weight of the pancreas in the adult human being: a biometric study. Anat Rec (Hoboken). 1926; 32: 119-132.

12. Ogilvie R. The island of Langerhans in 19 cases of obesity. JPathol. 1933; 37: $473-481$

13. Catanzaro R, Cuffari B, Italia A, Marotta F. Exploring the metabolic syndrome: Nonalcoholic fatty pancreas disease. World J Gastroenterol. 2016; 22: 7660-7675.

14. Kullberg J, von Below C, Lönn L, Lind L, Ahlström H, Johansson L. Practical approach for estimation of subcutaneous and visceral adipose tissue. Clin Physiol Funct Imaging. 2007; 27(3): 148-53.

15. Ildiko Lingvay, Victoria Esser, Jaime L. Legendre, Angela L. Price, Kristen M. Wertz, Beverley Adams-Huet, Song Zhang, Roger H. Unger, Lidia S.
Szczepaniak. Noninvasive Quantification of Pancreatic Fat in Humans. The Journal of Clinical Endocrinology \& Metabolism. 2009; 94(10): 4070-4076.

16. Zsóri G, Illés D, Ivány E, Kosár K, Holzinger G, Tajti M, Pálinkás E, Szabovik G, Nagy A, Palkó A, Czakó L. In New-Onset Diabetes Mellitus, Metformin Reduces Fat Accumulation in the Liver, But Not in the Pancreas or Pericardium. Metab Syndr Relat Disord. 2019; 17(5): 289-295.

17. Joanna Pieńkowska, Beata Brzeska, Mariusz Kaszubowski, Oliwia Kozak, Anna Jankowska, and Edyta Szurowska. MRI assessment of ectopic fat accumulation in pancreas, liver and skeletal muscle in patients with obesity, overweight and normal BMI in correlation with the presence of central obesity and metabolic syndrome. Diabetes Metab Syndr Obes. 2019; 12: 623-636.

18. Shen N, Li X, Zheng S, Zhang L, Fu Y, Liu X, Li M, Li J, Guo S, Zhang H. Automated and accurate quantification of subcutaneous and visceral adipose tissue from magnetic resonance imaging based on machine learning. Magn Reson Imaging. 2019

19. Xu L, Duanmu Y, Blake GM, Zhang C, Zhang Y, Brown K, Wang X, Wang P, Zhou X, Zhang M, Wang C, Guo Z, Guglielmi G, Cheng X. Validation of goose liver fat measurement by QCT and CSE-MRI with biochemical extraction and pathology as reference. European Radiology. 2017; 28(5): 2003-2012.

20. Cheng X, Blake GM, Brown JK, Guo Z, Zhou J, Wang F, Yang L, Wang X, Xu L. The measurement of liver fat from single-energy quantitative computed tomography scans. Quant Imaging Med Surg. 2017; 7(3): 281-291.

21. Guo Z, Blake GM, Li K, Liang W, Zhang W, Zhang Y, Xu L, Wang L, Brown JK, Cheng X, Pickhardt PJ. Liver Fat Content Measurement with Quantitative CT Validated against MRI Proton Density Fat Fraction: A Prospective Study of 400 Healthy Volunteers. Radiology. 2020; 294(1): 89-97.

22. Yao WJ, Guo Z, Wang L, Li K, Saba L, Guglielmi G, Cheng XG, Brown JK, Blake GM, Liu B. Pancreas fat quantification with quantitative CT: an MRI correlation analysis. Clin Radiol. 2020

23. LH, Huang Y, Zhou J, Liang XH, Xian J, Li L, Qin YF. Use of First-phase Insulin Secretion in Early Diagnosis of Thyroid Diabetes and Type 2 Diabetes Mellitus. Chin Med J. 2017; 130: 798-804.

24. Idilman IS, Tuzun A, Savas B, Elhan AH, Celik A, Idilman R, Karcaaltincaba M. Quantification of liver, pancreas, kidney, and vertebral body MRI-PDFF in non-alcoholic fatty liver disease. Abdom Imaging. 2015; 40(6): 1512-9.

25. Hu, H.H., K.S. Nayak, and M.I. Goran. Assessment of abdominal adipose tissue and organ fat content by magnetic resonance imaging. Obes Rev. 2011; 12(5): e504-15.

26. Rijzewijk LJ, van der Meer RW, Smit JW, Diamant M, Bax JJ, Hammer S, Romijn JA, de Roos A, Lamb HJ. Myocardial steatosis is an independent predictor of diastolic dysfunction in type 2 diabetes mellitus. J Am Coll Cardiol. 2008; 52(22): 1793-9.

27. Kitade H, Chen G, Ni Y, Ota T. Nonalcoholic Fatty Liver Disease and Insulin Resistance: New Insights and Potential New Treatments. Nutrients. 2017; 9(4).

28. Randle PJ, Garland PB, Hales CN, Newsholme EA. The glucose fatty-acid cycle. Its role in insulin sensitivity and the metabolic dis- turbances of diabetes mellitus. Lancet. 1963; 1: 785-789.

29. Seppala-Lindroos A, Vehkavaara S, Hakkinen A.M, Goto T, Westerbacka J. Sovijarvi A., Halavaara J., Yki-Järvinen H. Fat accumulation in the liver is associated with defects in insulin suppression of glucose production and serum free fatty acids independent of obesity in normal men. J Clin Endocrinol Metab. 2002: 87: 3023-3028.

30. Adiels M., Westerbacka J., Soro-Paavonen A., Hakkinen A.M., Vehkavaara S., Caslake M.J., Packard C., Olofsson S.O., Yki-Järvinen H., Taskinen M.R. Acute suppression of VLDL1 secretion rate by insulin is associated with hepatic fat content and insulin resistance. Diabetologia. 2007; 50: 2356-2365.

31. Taylor R. Banting Memorial lecture 2012: reversing the twin cycles of type 2 diabetes. Diab Med: J British Diab Assoc. 2013; 30: 267-75.

32. Samuel V.T, Shulman G.I. Mechanisms for Insulin Resistance: Common Threads and Missing Links. Cell. 2012; 148: 852-871.

33. Rehman K., Akash M.S.H. Mechanisms of inflammatory responses and development of insulin resistance: How are they interlinked?. Journal of Biomedical Science. 2016; 23: 87 .

34. Van Greevenbroek M.M.J, Schalkwijk C.G., Stehouwer C.D.A. Obesity-associated low-grade inflammation in type 2 diabetes mellitus: causes and consequences. Netherlands Journal of Medicine. 2013; 71: 174-187.

35. Lê KA, Ventura EE, Fisher JQ, Davis JN, Weigensberg MJ, Punyanitya M, Hu $\mathrm{HH}$, Nayak KS, Goran MI. Ethnic differences in pancreatic fat accumulation and its relationship with other fat depots and inflammatory markers. Diabetes Care. $2011 ; 34(2)$ : 485-90

36. van Raalte DH, van der Zijl NJ, Diamant M. Pancreatic steatosis in humans: cause or marker of lipotoxicity? Curr Opin Clin Nutr Metab Care. 2010; 13(4): $478-85$.

37. Heni M, Machann J, Staiger H, Schwenzer NF, Peter A, Schick F, Claussen CD, Stefan N, Häring HU, Fritsche A. Pancreatic fat is negatively associated with insulin secretion in individuals with impaired fasting glucose and/or impaired glucose tolerance: a nuclear magnetic resonance study. Diabetes Metab Res Rev. 2010; 26(3): 200-5.

38. Lu T, Wang Y, Dou T, Xue B, Tan Y, Yang J. Pancreatic fat content is associated with $\beta$-cell function and insulin resistance in Chinese type 2 diabetes subjects. Endocr J. 2019 Mar 28; 66(3): 265-270.

39. Tushuizen, M. E., Bunck, M. C., Pouwels, P. J., Bontemps, S., van Waesberghe, J. H., Schindhelm, R. K., Mari, A., Heine, R. J. \& Diamant, M. Pancreatic fat content and beta-cell function in men with and without type 2 diabetes. Diabetes care. 2007; 30(11): 2916-2921. 
40. Wong VW, Wong GL, Yeung DK. Fatty pancreas, insulin resistance, and betacell function: a population study using fat-water magnetic resonance imaging. Am J Gastroenterol. 2014; 109: 589-597.

41. van der Zijl NJ, Goossens GH, Moors CC. Ectopic fat storage in the pancreas, liver, and abdominal fat depots: impact on beta-cell function in individuals with impaired glucose metabolism. J Clin Endocrinol Metab. 2011; 96: 459-467.

42. Wicklow, B., Griffith, A. T., Dumontet, J. N., Venugopal, N., Ryner, L., \& Mcgavock, J. Pancreatic lipid content is not Aassociated with beta cell dysfunction in youth-onset Type 2 diabetes. Canadian Journal of Diabetes. 2013; 39(5): 398-404.

43. Robertson RP, Harmon J, Tran POT, Poitout V. Beta-cell glucose toxicity, lipotoxicity, and chronic oxidative stress in type 2 diabetes. Diabetes. 2004; 53(Suppl. 1): S119-S124.

44. Poitout V. Glucolipotoxicity of the pancreatic beta-cell: Myth or reality? Biochemical Society Transactions. 2008; 36(5): 901-904.

45. Jacqueminet S, Briaud I, Rouault C, Reach G, Poitout V. Inhibition of insulin gene expression by long-term exposure of pancreatic $\beta$-cells to palmitate is dependent on the presence of a stimulatory glucose concentration. Metabolism. 2000; 49: 532-536.

46. Briaud I, Kelpe CL, Johnson LM, Tran PO, Poitout V. Differential effects of hyperlipidemia on insulin secretion in islets of Langerhans from hyperglycemic versus normoglycemic rats. Diabetes. 2002; 51: 662-668.

47. Zhou YP, Grill VE. Long-term exposure of rat pancreatic islets to fatty acid inhibits glucose-induced insulin secretion and biosyntesis through a glucose fatty acid cycle. J Clin Invest. 1994; 93: 870-876.

48. Isserow, J.A., Siegelman, E.S. \& Mammone, J. Focal fatty infiltration of the pancreas: MR characterization with chemical shift imaging. AJR Am J Roentgenol. 1999; 173: 1263-1265.

49. Nghiem, D.D., Olson, P.R. \& Ormond, D. The "fatty pancreas allograft": anatomopathologic findings and clinical experience. Transplant Proc. 2004; 36: 1045-1047.

50. Lee, Y., Lingvay, I., Szczepaniak, L.S., Ravazzola, M., Orci, L. \& Unger, R.H. Pancreatic steatosis: harbinger of type 2 diabetes in obese rodents. Int J Obes (Lond). 2010; 34: 396-400.

51. Zha M, Xu W, Jones PM, Sun Z. Isolation and characterization of human islet stellate cells. Exp Cell Res. 2015; 341(1):61-66.

52. Zha M, Li F, Xu W, Chen B, Sun Z. Isolation and characterization of islet stellate cells in rat. Islets. 2014; 6(2): e28701.

53. Xu W, Liang J, Geng HF, Lu J, Li R, Wang XL, Lv Q, Liu Y, Wang J, Liu XK, Jones PM, Sun Z. Wingless-Type MMTV Integration Site Family Member 5a Is a Key Secreted Islet Stellate Cell-Derived Product that Regulates Islet Function. Int J Endocrinol. 2019 Apr 11; 2019: 7870109.

54. Xu W, Geng H, Liang J, Liu Y, Lv Q, Wang J, Li R, Wang XL, Liu XK, Jones PM, Sun ZL. Wingless-type MMTV integration site family member $5 \mathrm{a}$ is a key inhibitor of islet stellate cells activation. J Diabetes Investig. 2020; 11(2): 307-314.

55. Zhou Y, Li W, Zhou J, Chen J, Wang X, Cai M, Li F, Xu W, Carlsson PO, Sun Z. Lipotoxicity reduces $\beta$ cell survival through islet stellate cell activation regulated by lipid metabolism-related molecules. Exp Cell Res. 2019 Jul 1; 380(1): $1-8$.

56. Szczepaniak LS, Victor RG, Mathur R, Nelson MD, Szczepaniak EW, Tyer N, Chen I, Unger RH, Bergman RN, Lingvay I. Pancreatic steatosis and its relationship to beta-cell dysfunction in humans: racial and ethnic variations. Diabetes Care. 2012; 35(11): 2377-83.

57. Toledo-Corral CM, Alderete TL, Hu H, Nayak K, Esplana S, Liu T, Goran MI, Weigensberg MJ. Ectopic fat deposition in overweight and obese Minority Adolescents. J Clin Endorinol Metab. 2013 Mar; 98(3): 1115-21.

58. $\mathrm{Hu} \mathrm{HH}$, Chen J, Shen W. Segmentation and quantification of adipose tissue by magnetic resonance imaging. MAGMA. 2016; 29(2): 259-76.

59. Lorenzo Carlo Pescatori, Edoardo Savarino, Giovanni Mauri, Enzo Silvestri, Maurizio Cariati,Francesco Sardanelli, Luca Maria Sconfienza. Quantification of visceral adipose tissue by computed tomography and magnetic resonance imaging: reproducibility and accuracy. Radiol Bras. 2019; 52(1): 1-6.

60. Cheng X, Zhang Y, Wang C, Deng W, Wang L, Duanmu Y, Li K, Yan D, Xu L, Wu C, Shen W, Tian W. The optimal anatomic site for a single slice to estimate the total volume of visceral adipose tissue by using the quantitative computed tomography (QCT) in Chinese population. European Journal of Clinical Nutrition. 2018; 72(11): 1567-1575.

61. Wu Y, Guo Z, Fu X, Wu J, Gao J, Zeng Q, Fu H, Cheng X. The study protocol for the China Health Big Data (China Biobank) project. Quantitative Imaging in Medicine and Surgery. 2019; 9(6): 1095-1102.

62. Mari A, Tura A, Gastaldelli A, Ferrannini E. Assessing insulin secretion by modeling in multiple-meal tests: role of potentiation. Diabetes. 2002; 51 (Suppl. 1): S221-S226. 